\title{
UMA ANÁLISE DA AGROINDÚSTRIA CANAVIEIRA DO PARANÁ À GUISA DA MATRIZ DE CAPACIDADES TECNOLÓGICAS ${ }^{1}$
}

\author{
Elvanio Costa de Souza ${ }^{2}$ \\ Pery Francisco Assis Shikida ${ }^{3}$ \\ Jefferson Paulo Martins ${ }^{4}$
}

\begin{abstract}
Resumo - Este trabalho teve como objetivo analisar a matriz de capacidades tecnológicas da agroindústria canavieira paranaense, de modo a evidenciar suas características nos âmbitos dos investimentos, operação/produção, inovação e relações com a economia. Os resultados da matriz de capacidades tecnológicas indicaram que o fato de não existirem grandes concentrações de capacidades tecnológicas, para a gradação avançada, comum nessa agroindústria, é ainda fruto do secular paradigma subvencionista que imperou no setor até os anos de 1990. Não obstante, a preocupação com a sobrevivência setorial, principalmente no atual ambiente de desregulamentação, estava também evidenciada em vários âmbitos das capacidades tecnológicas retratadas por algumas usinas pesquisadas.
\end{abstract}

Palavras-chave: Capacidades tecnológicas, dinâmica, agroindústria canavieira e Paraná.

1 Este trabalho contou com o apoio do CNPq, sendo parte do Projeto de Pesquisa (PQ-CNPq) do $2^{\circ}$ co-autor. Uma versão deste paper foi laureada no XV Prêmio Paraná de Economia, do Conselho Regional de Economia do Paraná - CORECON-PR, em 2005. Os autores são gratos aos pareceristas desta Revista pelas profícuas críticas e sugestões. Recebido em 07/06/2005 Aceito em 15/09/2005.

2 Acadêmico do Curso de Economia e bolsista do Programa PIBIC-CNPq-UNIOESTE. Rua da Faculdade, 645, 85903-000 Toledo, PR. Colaborador do GEPEC - Grupo de Pesquisa em Agronegócio e Desenvolvimento Regional. E-mail: <elvanio@unioeste.br>.

3 Professor Adjunto do Curso de Economia e do Mestrado em Desenvolvimento Regional e Agronegócio da UNIOESTE-Toledo, bolsista de Produtividade em Pesquisa do CNPq e pesquisador GEPEC. Email:<pfashiki@unioeste.br>.

4 Contador, Mestre em Desenvolvimento Regional e Agronegócio da UNIOESTE-Toledo. Rua da Faculdade, 645, 85903-000 Toledo, PR. E-mail: <jeffer.m@terra.com.br>. 


\section{Introdução}

Este trabalho objetivou analisar a matriz de capacidades tecnológicas da agroindústria canavieira paranaense, de modo a evidenciar as principais características dos âmbitos dos investimentos, operação/produção, inovação e relações com a economia desse importante setor.

O Paraná está inserido no grupo dos maiores estados produtores da agroindústria canavieira do país, detendo 7,9\% da produção nacional de cana-de-açúcar, 7,4\% da produção de açúcar e 8,3\% da produção de álcool (safra 2003/2004), dados esses que o qualificam como o segundo maior produtor, sendo superado apenas por São Paulo (ASSOCIAÇÃO DE PRODUTORES DE ÁLCOOL E AÇÚCAR DO ESTADO DO PARANÁ - ALCOPAR, 2005).

Segundo a ALCOPAR (2005), a agroindústria canavieira do Paraná conta com 27 unidades produtoras de açúcar e, ou, álcool - de modo geral de perfil moderno -, atingindo economicamente 126 municípios e gerando aproximadamente 74 mil empregos diretos. A produção de cana do Paraná tem, com sua peculiaridade, acompanhado as vicissitudes da indústria sucroalcooleira, mediante investimentos na ampliação da área de cultivo e no volume de cana produzida, além da elevação da produtividade e da melhoria da qualidade da matéria-prima (Shikida et al., 2004).

O processo de desregulamentação da agroindústria canavieira nacional, desencadeado inicialmente nos anos de 1990 - em que "o papel do Estado mudou, ele agora é mais coordenador do que interventor" (Vian, 2003, p.11) -, vem atingindo toda a economia desta atividade produtiva, seja em nível nacional, seja no contexto paranaense. As mudanças institucionais que estão ocorrendo no setor têm influenciado as decisões dos seus agentes econômicos (usineiro, fornecedor, indústria automobilística, exportador etc.), de modo que a modernização agrícola e industrial vem se tornando condição sine qua non para a sobrevivência desse mercado, no qual a adoção de diferentes estratégias competitivas deixa evidente a diversidade de interesses (Vian, 2003). 
Diante desse cenário competitivo, muitas unidades produtivas, sob a lógica do paradigma subvencionista que reinou na agroindústria canavieira até o início dos anos de 1990, sucumbiram. Destarte, vem predominando na agroindústria canavieira a lógica de acumulação intensiva, seja com progresso técnico, redução do emprego e, ou, aumento da produção diferenciada (açúcar líquido, invertido, orgânico etc.), isto é, está em vigor o paradigma tecnológico.

No Paraná, as mudanças que afetaram a agroindústria canavieira também foram sentidas, exigindo uma reorganização dos produtores, porquanto a responsabilidade pela coordenação do setor passou a ser delegada fundamentalmente ao mercado e às instituições que nele atuam (Shikida et al., 2004).

Quais são, no entanto, as capacidades tecnológicas da agroindústria canavieira do Paraná? Analisar essa característica de desempenho setorial numa óptica microeconômica, de modo que a lacuna teórica-prática seja menos sentida, poderá contribuir para elucidar questões dessa atividade produtiva, as quais outros delineamentos não permitem inferir. Dessa forma, espera-se que a exposição da matriz de capacidades tecnológicas da agroindústria canavieira paranaense possa evidenciar o quadro atual da dinâmica dos investimentos, operação/produção, inovação e relações com a economia desse importante setor.

Isso posto, este trabalho foi dividido em cinco partes, incluindo esta introdução. A segunda parte versa sobre uma breve síntese da evolução da agroindústria canavieira no Paraná. Na terceira, quarta e quinta partes são ressaltados, respectivamente, o referencial teórico, o referencial analítico e o procedimento metodológico. Os resultados e discussões derivados da aplicação de questionários compõem a sexta parte. Por último, discutem-se as considerações finais. 


\section{Síntese da evolução da agroindústria canavieira no Paraná}

Com efeito, o Paraná apresentou durante um bom tempo uma economia baseada no setor de subsistência e com praticamente nenhuma influência na área sucroalcooleira. Teve sua base econômica consubstanciada na mineração, tropeirismo, exploração da erva-mate e da madeira e, mais recentemente, no café. A falta de capital e terras necessárias, dentre outros fatores, contribuiu para a não-tradição do estado na produção de cana-de-açúcar (Shikida, 2001).

Não obstante, de acordo com Kaefer e Shikida (2000), a agroindústria canavieira paranaense só despontou a partir do PROÁLCOOL, já nos anos de 1980, ocorrendo aumento considerável na produção, principalmente de cana-de-açúcar e de álcool.

A Tabela 1 evidencia a evolução histórica da produção de cana-de-açúcar, açúcar e álcool paranaenses e da sua participação percentual no total brasileiro, no período entre as safras de 1975/76 e 2003/04. Os dados dessa tabela indicam que a agroindústria canavieira paranaense, a despeito de algumas breves oscilações, deu um grande salto, mormente quando passou a representar mais do que $6,4 \%$ do total de cana produzido no país (a partir da safra de 1994/95), superando a casa dos 15 milhões de toneladas. Da mesma forma, a participação da produção paranaense no total produzido de álcool e açúcar no Brasil apresentou relativa evolução no período analisado, o que permitiu ao Paraná situar-se atualmente entre os maiores produtores nacionais de cana-de-açúcar. 
Elvanio Costa de Souza, Pery Francisco Assis Shikida \& Jefferson Paulo Martins

Tabela 1 - Indicadores da evolução da cana-de-açúcar no Paraná - 1975/ 76 a $2003 / 04$

\begin{tabular}{c|c|r}
\hline Safra & $\begin{array}{r}\text { Produção } \\
\text { de Cana (t) }\end{array}$ & $\begin{array}{r}\% \\
\text { Tc } \\
\text { Nac }\end{array}$ \\
\hline $1975 / 76$ & 1.905 .534 & \\
$1976 / 77$ & 2.300 .991 & \\
$1977 / 78$ & 2.541 .203 & \\
$1978 / 79$ & 2.982 .320 & \\
$1979 / 80$ & 3.299 .326 & \\
$1980 / 81$ & 4.207 .483 & \\
$1981 / 82$ & 4.698 .282 & \\
$1982 / 83$ & 6.283 .542 & \\
$1983 / 84$ & 9.066 .571 & \\
$1984 / 85$ & 7.619 .858 & \\
$1985 / 86$ & 10.568 .930 & \\
$1986 / 87$ & 10.917 .716 & \\
$1987 / 88$ & 10.875 .423 & \\
$1988 / 89$ & 10.273 .412 &
\end{tabular}

Fonte: Dados compilados de ALCOPAR (2005) e UNICA (2004).

* Significativo a $5 \%$. 
Houve também considerável evolução do número de unidades produtoras de cana moída no Paraná entre as safras de 1978/79 e 2003/2004. Na safra de 1978/79 havia apenas quatro unidades produtoras no estado, e já na safra de 1985/86, com o impulso dado pelo PROÁLCOOL, esse número era de 25 unidades. Na safra de 1990/91, o número de unidades produtoras aumentou para 29. Atualmente, o Paraná conta com 27 unidades produtoras de cana moída (ALCOPAR, 2005).

Se o PROÁLCOOL contribuiu para alavancar o desenvolvimento de novas regiões produtoras como o Paraná (Carvalheiro, 2003), a sua crise explicitou a inabilidade do estado em regulamentar o setor, principalmente nos anos de 1990, com o processo de afastamento do governo federal de diversos setores produtivos da economia, parte de um processo mais amplo, ou seja, a política neoliberal de minimização da participação do estado (Moraes, 2002).

Dentro desse contexto ocorreram várias transformações na agroindústria canavieira brasileira e paranaense, como: os preços do açúcar (no mercado interno), do álcool anidro e da cana-de-açúcar passaram a não mais ser tabelados; e foram liberadas as exportações açucareiras (Alves, 2002).

Essas transformações geraram grande preocupação para os estados produtores que estavam despreparados para essa nova conjuntura, porquanto as regiões com menor progresso técnico e condições para a produção de cana não conseguiam se manter sem as benesses do estado. Ressalta-se, aqui, a importância de estudar as capacidades tecnológicas da agroindústria canavieira paranaense, uma vez que a dinâmica voltada para a criação e renovação das capacidades tecnológicas é fator essencial para o sucesso competitivo de qualquer empresa. 


\section{Referencial teórico}

$\mathrm{O}$ ambiente concorrencial mais acirrado está contribuindo para que o processo produtivo das empresas seja cada vez mais prático e eficaz, sobretudo na aplicação do novo conhecimento a situações empíricas que resultem no rápido avanço tecnológico. Essa dinâmica, cuja manifestação mais explícita se relaciona com a ocorrência do grande número de inovações, é auto-alimentadora, continuada e interativa. Nesse contexto, pela importância que vem assumindo enquanto determinantes da competitividade e mesmo da sobrevivência das empresas, há a priorização de fatores como o conhecimento e existência de pessoal qualificado como potencializadores do desenvolvimento tecnológico (Rocha; Ferreira, 2001).

Embora na teoria econômica ainda não se verifique um arcabouço teórico unívoco, necessário ao entendimento da dinâmica tecnológica, existem alguns instrumentais analíticos, mutuamente excludentes ou não, que tratam dos vários aspectos da dinâmica tecnológica (Shikida, 2001).

Neste estudo, optou-se pelo referencial teórico neoschumpeteriano para interpretar os principais condicionantes da dinâmica tecnológica da agroindústria canavieira no Paraná. Essa opção baseou-se no fato de que a competitividade está intrinsecamente relacionada com a capacidade da empresa em formular e implementar estratégias concorrenciais (fundadas não somente na parte técnica, mas também no desempenho da firma e da capacidade financeira, nas relações com fornecedores e usuários, na imagem conquistada, na diferenciação de seus produtos, no grau de concentração do mercado etc.) que lhe permitam conservar, de forma duradoura, uma posição sustentável no mercado. Nesse sentido, o sucesso competitivo perpassa por uma dinâmica voltada para a criação e renovação das capacidades tecnológicas que irão aferir vantagens competitivas para as empresas (Coutinho et al., 1993).

Reportando inicialmente ao termo tecnologia, Dosi (1984) o definiu como um conjunto de partes do conhecimento, práticos e, ou, teóricos, que 
adquire especificidade ao assumir formas concretas de aplicação a determinada atividade. Esse conjunto envolve desde métodos, procedimentos, experiências e know-how até mecanismos e equipamentos, sendo a busca de novas soluções técnicas em processos e, ou, produtos caracteristicamente endógena e dinâmica, afetando não só a competitividade da firma, como também o emprego, a renda e as instituições.

Para Salles Filho (1993, p.90), a identificação da tecnologia “[... i implica a percepção de possíveis alternativas atuais e de possíveis desenvolvimentos futuros. Em outras palavras, conforma um conjunto limitado, mas não bem definido, de caminhos a seguir".

Nesse contexto, a busca por novas tecnologias contém uma particularidade, isto é, os resultados daí derivados não são conhecidos ex-ante e a taxa de adoção de uma tecnologia, ou mesmo sua direção, está associada às expectativas quanto ao futuro do progresso tecnológico (Dosi, 1984). Dessa forma, as decisões de inovação e investimento serão caracterizadas pela incerteza, em que o mercado funciona como uma espécie de fornecedor de feedbacks ao processo de geração de novas tecnologias, vetando ou sancionando desenvolvimentos prováveis (Rosenberg, 1982).

Como a dinâmica tecnológica, fundamentada pelo processo inovativo, não é algo aleatório, a interação entre as condições estruturais-ambientais (que demarcam as possibilidades decisórias das firmas quanto à ocupação de mercados) e as estratégias competitivas selecionadas pelas firmas (realizadas sob condições de incerteza, dentro de leques de possibilidades) determinam a evolução das estruturas de mercado (Canuto, 1991, citado por Shikida, 2001).

Nessa perspectiva está a dimensão dinâmica e diruptiva do conceito de concorrência, no qual as noções correlatas de firmas (revista dinamicamente como de base técnica mutável) e mercado (revista dinamicamente como o locus da concorrência) são mais de 
interdependência do que de separação dicotômica. Portanto, torna-se necessário enfatizar a questão da dinâmica tecnológica inserida no locus da concorrência, ou seja, no eixo firma-mercado, em que a firma é influenciada por inovações introduzidas mediante decisões empresariais estratégicas que se baseiam fortemente nas condições de seleção e de apropriabilidade da inovação sob a forma de lucros e com a presença não eliminável de incerteza nessas decisões (Possas, 1991).

A dinâmica tecnológica, entendida como um processo de adoção contínua de inovações, depende do conhecimento que é acumulado ao longo do tempo pelo processo de aprendizado, que pode ser mediante learningby-doing (LBD), learning-by-using (LBU), learning-by-searching (LBS) e, ou, learning-by-interacting (LBI) (Rosenberg, 1982; Cário; Pereira, 2001).

Nesse ínterim, o paradigma tecnológico pode ser definido como o pacote ou padrão de procedimentos que orienta a investigação sobre um problema tecnológico, com base em princípios altamente seletos derivados das cumulatividades de conhecimentos tecnológicos, de oportunidades inovativas e das características particulares assumidas pelas interações entre aspectos científicos, produtivos e institucionais. A trajetória tecnológica pode ser definida como desdobramentos próprios no interior de um paradigma tecnológico, correspondendo, em geral, às respostas aos diversos trade-offs estabelecidos entre as variáveis tecnológicas. A trajetória tecnológica representa a maneira pela qual o paradigma tecnológico evolui (Dosi, 1984).

Segundo Shikida (2001), as empresas brasileiras têm procurado adequar suas trajetórias tecnológicas em face de um contexto de progressivas introduções de inovações econômicas, num ambiente de crescente internacionalização dos mercados mundiais.

No tocante à competitividade, Oliveira (2003) destacou a complexidade que envolve esse termo, porquanto o mesmo abrange uma série de variáveis que tornam premente a especificação do contexto no qual se 
está trabalhando, podendo-se tratar de competitividade entre e intrafirmas, em determinadas estruturas produtivas, entre e intranações, no curto ou no longo prazo, ex-ante ou ex-post etc. Logo, a complexidade do sentido competitividade exige um foco de análise; se não, pode-se incorrer no equívoco de utilizá-lo de modo tão genérico, a ponto de perder o seu significado.

Com relação ao tratamento conceitual de competitividade, Coutinho et al. (1993) chamaram a atenção para o fato de esse fenômeno estar diretamente relacionado às características apresentadas por uma firma ou um produto, ligadas tanto ao desempenho no mercado (market-share) ou à eficiência técnica dos processos produtivos adotados pela firma (best-practices). Contudo, a noção de competitividade deve ser dinâmica, pois tanto o desempenho quanto a eficiência são resultados de capacitações acumuladas e estratégias competitivas adotadas pelas firmas, em face de suas percepções quanto ao processo concorrencial e ao meio ambiente econômico no qual estão inseridas.

Logo, a competitividade neste trabalho é entendida como a capacidade da empresa em implementar estratégias concorrenciais que lhe possibilitem aumentar ou, mesmo, preservar uma posição sustentável no mercado. Não obstante, a competitividade também "depende da criação e renovação das vantagens competitivas por parte das empresas, em consonância com os padrões de concorrência vigentes, idiossincráticos de cada setor da estrutura produtiva" (Haguenauer et al., 1996, p.196).

\section{Referencial analítico}

Neste contexto, para analisar a dinâmica tecnológica da agroindústria canavieira no Paraná este trabalho remeteu-se ao conceito de capacidades tecnológicas, porquanto o sucesso competitivo perpassa por uma dinâmica voltada para a criação e renovação das capacidades tecnológicas [Once firm-level technological change is understood as a continuous process to absorb or create technical knowledge, determined partly 
by external inputs and partly by past accumulation of skills and knowledge [...] (Lall, 1992, p.2-3)], que irão aferir vantagens competitivas para a empresa.

Para Lall (1992), além da capacidade de adquirir, assimilar, usar, adaptar, mudar ou criar tecnologia, a capacidade tecnológica das empresas é a própria capacidade destas de gerar inovações, a qual pode ser dividida em três níveis distintos: básica, intermediária e avançada (simple routine, adaptive duplicative, innovative risky). A capacidade básica trata-se do conhecimento mínimo sobre a tecnologia em uso, necessária para as empresas se manterem no mercado. A intermediária requer a melhoria da tecnologia em uso (num patamar maior do que a observada no nível básico); para tanto são necessários maiores conhecimentos científicos selecionados, pessoal qualificado e algum direcionamento para pesquisa e desenvolvimento (P\&D). A capacidade avançada, além de requerer a melhoria da tecnologia em uso, procura criar novas tecnologias, de forma a maximizar o desempenho e a eficiência das estratégias competitivas adotadas pelas firmas.

Para caracterizar a dinâmica tecnológica - entendida como um processo de adoção/melhoria contínua de capacidades tecnológicas de uma empresa - Lall (1992) dividiu as atividades da empresa em três grupos/ âmbitos (não estanques entre si): perfil dos investimentos (representa as habilidades de preparação para a identificação e obtenção de novas tecnologias de projeto, equipamento e gerenciamento - dividido em investimento inicial e execução de projetos); perfil da produção (como a empresa trata do aspecto da produção sob três grupos de análise: engenharia de produto, de processo e de gestão industrial); e perfil de relacionamento com a economia (capacidade de transmitir e receber informações, habilidades e tecnologias inseridas no contexto dos ambientes técnico, institucional e organizacional). 
Shikida (2001), ao analisar a dinâmica tecnológica da agroindústria canavieira do Paraná, por meio de estudos de caso das Usinas Sabarálcool e Perobálcool, enfatizou minuciosamente as capacidades tecnológicas dessas empresas em três âmbitos prioritários: operação (produção, administração e comercialização), investimento e inovação.

À guisa de quatro trabalhos (Dahlman et al., 1985; LALL, 1992; Ruffoni; Zawislak, 1999; Shikida, 2001), montou-se o Quadro 1, para identificação dos principais condicionantes/características da dinâmica tecnológica da agroindústria canavieira no Paraná. 
Elvanio Costa de Souza, Pery Francisco Assis Shikida \& Jefferson Paulo Martins

Quadro 1 - Matriz de capacidades tecnológicas

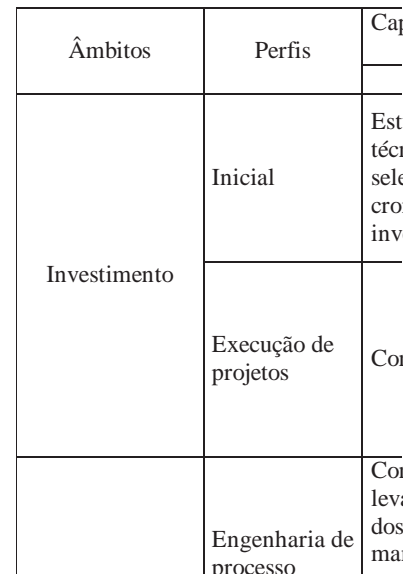

Fonte: Adaptado a partir de Dahlman et al. (1985), Lall (1992), Ruffoni e Zawislak (1999) e Shikida (2001). 
De acordo com Ruffoni e Zawislak (1999), para as empresas sobreviverem ao processo dinâmico da economia é necessário que tenham capacidade de mudar, adaptar e inovar, ou seja, é preciso um bom aporte de capacidade tecnológica. A partir do conhecimento das atividades realizadas por uma empresa, em seus mais variados setores e numa amplitude que englobe tanto aspectos a jusante quanto a montante dela, podem-se obter os perfis dos investimentos, da produção/operação, da inovação e do relacionamento com a economia, identificando, assim, os níveis de capacidades tecnológicas das usinas e destilarias.

Apoiadas nesse instrumental (capacidades tecnológicas), as noções de firmas e mercado são de fato de interdependência dinâmica, o que vem ao encontro do fato de a questão da dinâmica tecnológica estar inserida no locus maior da concorrência, em que os ambientes micro e macroeconômicos interagem no mesmo espaço, o qual está em consonância com os padrões de concorrência vigentes e idiossincráticos de cada setor da estrutura produtiva. Ademais, a interação entre as condições estruturais-ambientais, que demarcam as possibilidades decisórias das firmas quanto à ocupação de mercados, juntamente com as estratégias competitivas selecionadas pelas firmas (realizadas sob condições de incerteza, dentro de possibilidades que se baseiam fortemente nas condições de seleção e de apropriabilidade do desenvolvimento tecnológico sob a forma de lucros), configuram-se como determinantes da dinâmica tecnológica da firma.

\section{Procedimento metodológico}

Especificamente nesta pesquisa, o primeiro passo foi realizado a partir da exploração de dados secundários, extraídos de um limitado número de referências que tratam do tema agroindústria canavieira do Paraná. Feito esse balizamento, procurou-se identificar qual a matriz de capacidades tecnológicas desse setor produtivo, a partir de uma realidade mais completa e real dos fatos, caracterizaria o problema pesquisado. 
Nesse sentido, a fundamentação metodológica deste trabalho assentouse principalmente nas percepções dos elementos pesquisados sobre o seu contexto de vida real (Campomar, 1991; Godoy, 1995), mais especificamente sobre as capacidades tecnológicas das usinas paranaenses.

As informações, dessa forma, foram coletadas por intermédio de pesquisa de campo (field study), via técnica de interrogação mediante a aplicação de questionários in loco, ou seja, numa reunião da ALCOPAR, que congregou os associados e dirigentes das usinas paranaenses. Cumpre salientar que esse tipo de pesquisa "tem por objetivo a coleta de elementos não disponíveis que, ordenados sistematicamente de acordo com processos adequados, possibilitam o conhecimento de determinada situação, hipótese ou norma de procedimento" (Munhoz, 1989, p.85).

Adotou-se essa metodologia pela importância do processo participativo - interação entre o pesquisador e os pesquisados -, porquanto ao envolver uma amostra relativamente homogênea (o foco, no caso, é a agroindústria canavieira, a qual todos pertencem) essa técnica de interrogação permitiu maior flexibilidade de ajustamento aos mais variados tipos de problemas e de informações, aprofundando-se, caso fosse necessário, em algumas discussões/dúvidas e, ou, respostas (Gil, 2000).

A condução da aplicação de questionários, feita pelos próprios proponentes desta pesquisa, mesmo tendo perguntas previamente definidas, assumiu, assim, um caráter não- metódico, haja vista a dependência do contexto da conversação e das interações surgidas ad hoc; isto é, além das informações obtidas via questionário, a coleta dos dados ocorreu por meio de observação espontânea do pesquisador no ato da pesquisa. Isso implica dizer que o contato direto dos pesquisadores com o seu objeto possibilitou maximizar a exploração da temática estudada, de modo que a obtenção de dados inerentes à aplicação do questionário perpassou também pela captação do feeling do respondente. Para isso, o pesquisador precisou estar preparado e em condições de estabelecer um rapport adequado com o seu pesquisado (Yin, 2001). Com efeito, num 
processo de simples aplicação de questionário feita por terceiros (que não tem a base de conhecimento que o pesquisador possui), muitas vezes as informações ou demais dados não são captados com a devida clareza.

De 20 associados presentes no ato da coleta de dados (o número de associados total é de 24) foi possível obter, em virtude do tempo disponível (vale ressaltar que a aplicação do questionário foi face a face), oito questionários prontamente respondidos. Àqueles que não puderam responder ao questionário durante a pesquisa in loco (na ALCOPAR), ele lhes foi enviado via $e$-mail, sendo três questionários respondidos. Portanto, 11 foi o número de respondentes, perfazendo $46 \%$ do total da população, índice relevante para os propósitos da representatividade amostral, conforme atestado em trabalhos anteriores como o de Shikida e Alves (2001). Na seção seguinte são apresentados os resultados e as discussões.

\section{Resultados e discussões}

Este item teve como escopo analisar a matriz de capacidades tecnológicas da agroindústria canavieira do Paraná, evidenciando-se, assim, o atual quadro da dinâmica dos investimentos, operação/produção, inovação e relações com a economia desse importante setor produtivo.

Cumpre relatar, contudo, com base no que foi exposto na revisão teórica, que essas capacidades tecnológicas da agroindústria canavieira do Paraná estão inseridas no locus da concorrência, as quais foram, e são, influenciadas por decisões empresariais estratégicas, que se baseiam fortemente na apropriabilidade dos lucros. Dessa forma, está incluso nessa perspectiva o caráter dinâmico, no qual o que se tem hoje na empresa é fruto de estratégias passadas, e o futuro dependerá daquilo que está sendo feito no presente e das interações provenientes do eixo firma-mercado em cada delimitação temporal. Para Coutinho et al. (1993), a análise da competitividade deve levar em conta a cumulatividade das vantagens competitivas adquiridas pelas empresas. 
No Quadro 2, expõe-se a matriz de capacidades tecnológicas da agroindústria canavieira do Paraná; frisa-se, contudo, que os âmbitos do investimento, operação/produção, inovação e relações com a economia não são estanques, existindo interações dinâmicas entre eles.

Quadro 2 - Matriz de capacidades tecnológicas da agroindústria canavieira do Paraná, segundo o percentual de ocorrências

\begin{tabular}{|c|c|}
\hline Âmbitos & \\
\hline \multirow{2}{*}{ Investimento } & Inicial \\
\hline & Execução \\
\hline \multirow{3}{*}{ Operação/Produção } & Engenhari \\
\hline & Engenhari \\
\hline & Gestão inc \\
\hline Inovação & $\begin{array}{l}\text { Capacidad } \\
\text { de produtc } \\
\text { desenvolv }\end{array}$ \\
\hline $\begin{array}{c}\text { Relações com a } \\
\text { economia }\end{array}$ & $\begin{array}{l}\text { Inserção } n \\
\text { organizaci }\end{array}$ \\
\hline
\end{tabular}

Fonte: Dados da pesquisa.

No âmbito do investimento, verificou-se que todas as usinas pesquisadas possuem capacidades tecnológicas - para a realização de investimentos iniciais - no estágio do nível intermediário. Isso implica dizer que essas usinas, durante a realização de um investimento inicial qualquer, procuram realizar estudos de viabilidade técnico-econômica, seleção do local e cronograma de investimentos, além da negociação de contratos com fornecedores e consultas a sistemas de informação. Isso é perfeitamente plausível para investimentos do porte da agroindústria canavieira, que demandam uma monta considerável de capital (seja próprio e, ou, de terceiro) e, por consequiência, um minucioso plano de investimento inicial.

Quanto à execução de projetos, houve certo equilíbrio, mas ainda assim a maior parte das usinas pesquisadas $(52 \%)$ possuía capacidades tecnológicas no nível intermediário, que englobava a seleção do melhor fornecedor de equipamentos, recrutamento e treinamento de pessoal 
qualificado e engenharia detalhada. Um pouco menos da metade (48\%) possuía, nesse quesito, capacidade tecnológica avançada para a execução de projetos (mas apresentando apenas desenho do processo básico). Tal distribuição percentual ocorre porque, amiúde, as empresas do setor sucroalcooleiro dependem mais de equipamentos advindos de fornecedores de insumos (mormente maquinários) do que da fabricação do próprio equipamento. $\mathrm{O}$ desenho e fabricação dos equipamentos são comumente feitos por empresas a jusante das usinas.

No âmbito da operação/produção, verificou-se certa heterogeneidade em termos de capacidades tecnológicas da amostra das usinas do Paraná. No quesito engenharia de processo, notou-se que boa parte das usinas (39\%) estava capacitada, em nível básico (controle de qualidade, levantamento e análise dos problemas, manutenção preventiva e assimilação de processo tecnológico). Outrossim, uma fração igual à anterior (39\%) encontrava-se no estágio do nível intermediário, que diz respeito à redução de custos, modificação de novas tecnologias de processo, adaptação de processo aos novos produtos e melhoria na qualidade dos produtos. No nível avançado, que compreende a inovação própria de processo em departamento de $\mathrm{P} \& \mathrm{D}$, verificou-se um percentual menor de usinas inseridas (22\%). Vale dizer que certas usinas até buscam esse tipo de inovação algumas vezes, mas não continuamente.

Quanto à engenharia de produto, percebeu-se uma fração (33\%) de usinas tecnologicamente capacitadas no nível avançado (inovação própria de produto em departamento de $\mathrm{P} \& \mathrm{D}$ ). Engenharia reversa e pequenas adaptações às necessidades do mercado (características de capacidade tecnológica básica) eram práticas comuns em $42 \%$ das usinas pesquisadas, enquanto outra parte, $25 \%$, possuía capacidades em nível intermediário (modificação de produtos adquiridos por licenciamento).

No que diz respeito à gestão industrial, $47 \%$ das usinas respondentes apresentavam capacidades tecnológicas enquadradas nos níveis básico e intermediário, respectivamente. O nível básico, na gestão industrial, compreende o estudo geral dos métodos e dos tempos de trabalho e o 
controle de estoques, e o nível intermediário refere-se ao monitoramento da produtividade e à coordenação melhorada. Apenas uma usina (que corresponde a $6 \%$ da amostra) afirmou estar, nesse perfil, no nível avançado, que compreende a venda de pacotes tecnológicos ou licenciamento de tecnologia para terceiros. Contudo, a respondente fez questão de citar que tal prática existe, mas não é uma constante.

No âmbito da inovação, notou-se que $36 \%$ das usinas pesquisadas estavam com capacidades tecnológicas de nível básico, que se refere ao conhecimento mínimo sobre a tecnologia em uso, necessária para as empresas se manterem no mercado. Outros $36 \%$ estavam inseridos no nível intermediário (apresentam conhecimentos científicos, pessoal qualificado e algum direcionamento para $\mathrm{P} \& \mathrm{D}$ ). Cerca de $28 \%$ das usinas estavam inseridas no nível avançado, que envolve forte aparato de $\mathrm{P} \& \mathrm{D}$, procurando-se criar/deter novas tecnologias. Tal assertiva corrobora a relativamente pouca fração de usinas que possuem capacidades tecnológicas para o nível avançado no âmbito da operação/produção (a média dos três perfis desse âmbito foi de 20\%).

Quanto ao âmbito das relações com a economia, percebeu-se que a maioria das usinas (44\%) se enquadrava nas capacidades tecnológicas de nível básico, que englobava a obtenção de bens e serviços locais, troca de informações com fornecedores, cooperação, alianças e afiliações em nível básico. Cerca de $35 \%$ das usinas pesquisadas possuíam capacidades tecnológicas em nível intermediário, que diz respeito aos projetos realizados com clientes e fornecedores, ligações com instituições de C\&T (Ciência \& Tecnologia), cooperação, alianças e afiliações em nível intermediário. Quanto ao nível avançado (P\&D cooperativo, venda de pacotes tecnológicos ou licenciamento de tecnologia para terceiros, cooperação, alianças e afiliações em nível avançado), $21 \%$ dos respondentes disseram estar inseridos nesse nível, mas, destes, quase a metade das empresas se inseria de forma parcial ou descontínua. Tais dados vão de encontro ao que Shikida e Frantz (2002, p. 202) citaram para o caso das relações com a economia experimentada pelas agroindústrias canavieiras do Paraná: “[...] é válida também a máxima 
de que ações coletivas, devidamente coordenadas, possuem uma força maior que cada ação tomada isoladamente".

Destaca-se, pelo que foi exposto, que as usinas da agroindústria canavieira paranaense estavam situadas, maiormente, nos níveis intermediário e básico, nesta ordem de importância. O Quadro 3, que evidencia nas áreas hachuradas as maiores concentrações de percentuais acusados, retrata muito bem essa assertiva.

Quadro 3 - Maiores concentrações de respostas das usinas pesquisadas diante de suas capacidades tecnológicas

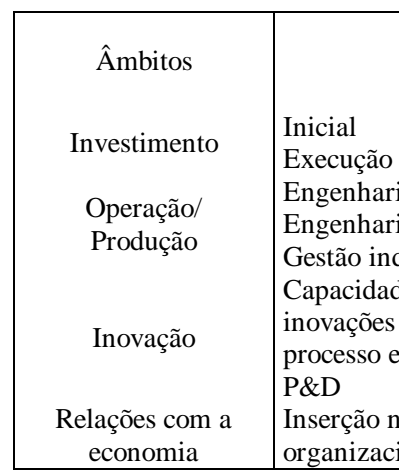

Fonte: Dados da pesquisa.

Nota: * As áreas hachuradas representam as ocorrências dos maiores percentuais pesquisados.

Conforme pode ser visto nos Quadros 2 e 3, a capacidade tecnológica avançada não apresentou nenhuma grande expressão participativa, dada pela maioria percentual (o único caso de destaque é na execução de projetos, com 48\%).

Como corolário do exposto no Quadro 3, tem-se que no âmbito do investimento a maioria das usinas pesquisadas se enquadrava no nível intermediário, o que vai de encontro ao que de fato ocorre na agroindústria canavieira paranaense. No âmbito da operação/produção, destacam-se 
as capacidades tecnológicas voltadas para a engenharia de processo e gestão industrial em níveis básico e intermediário, com a ressalva de que as capacidades tecnológicas direcionadas à engenharia de produto se enquadram mais no nível básico. Entre os motivos para essa realidade está a estrutura de mercado, na qual a agroindústria canavieira está mais próxima, ou seja, a estrutura de oligopólio competitivo, em que não é comum a concorrência por diferenciação de produtos, havendo, portanto, outras formas de competição. Destarte, uma das características desse setor é a homogeneidade dos produtos, tornando-se "menos" necessária a utilização de departamentos de $\mathrm{P} \& \mathrm{D}$ para a criação de novos produtos, no intuito de ganhar mercado. Os âmbitos da inovação e relações com a economia corroboram, também, o fato de a maior parte das empresas possuir capacidades tecnológicas básica e intermediária.

Embora o Quadro 3 evidencie o agregado desta pesquisa (os resultados de maiores expressões percentuais e, portanto, o perfil geral do estado), há, conforme visto no Quadro 2, várias dimensões de capacidades tecnológicas convivendo no mesmo ambiente econômico, sendo mais destacados, conforme já frisado, os níveis básico e intermediário. Explicitando essa discussão de uma forma mais analítica, notou-se que no Paraná - no âmbito das capacidades tecnológicas e, por analogia, no âmbito das estratégias tecnológicas - coexistem produtores com distintas gradações de avanços tecnológicos. Isso demonstra, por sua vez, a assimilação de um paradigma tecnológico como modelo de sobrevivência na agroindústria canavieira, que vai seguir dinâmica própria, a depender evidentemente de cada unidade produtora, mas circunscrita ao novo contexto de desregulamentação setorial, que tornou premente a minimização de custos, o desenvolvimento de best-practices e o aproveitamento cada vez mais intensivo de velhos e novos subprodutos. Quem vem fazendo isso está se diferenciando dos congêneres com atributos que lhe garante, a priori, possibilidades de melhor desempenho no mercado. 


\section{Considerações finais}

Os resultados da matriz de capacidades tecnológicas da agroindústria canavieira do Paraná, a partir do perfil das usinas que se dispuseram a responder ao questionário aplicado, evidenciaram que esse setor produtivo possui perfis coerentes com a sua dinâmica competitiva. $O$ fato de não existirem grandes concentrações de capacidades tecnológicas para a gradação avançada, comum na agroindústria canavieira, é ainda fruto do secular paradigma subvencionista que imperou no setor até os anos de 1990 (Shikida, 1997).

As preocupações crescentes com a sobrevivência setorial, no atual ambiente de desregulamentação (em que importa, sobretudo, estar atento à apuração dos custos, ao desenvolvimento de novas tecnologias e ao aproveitamento cada vez maior de subprodutos), estão também, no entanto, evidenciadas em vários âmbitos das capacidades tecnológicas retratadas pelas usinas pesquisadas. Desse modo, as usinas que estavam adotando perfis de capacidades tecnológicas numa gradação maior estavam também criando vantagens competitivas importantes para a sua permanência no setor sucroalcooleiro.

Com base nos apontamentos ora realizados e de acordo com Azevedo (2004), pode-se dizer que problemas como a dificuldade intrínseca de coordenação entre a quantidade ofertada e a quantidade demandada de açúcar e álcool estão mais fortes no atual momento de desregulamentação da agroindústria canavieira. Ademais, as mudanças tecnológicas (por exemplo carros bi e tricombustível) vêm afetando cada vez mais as perspectivas da agroindústria canavieira. Tais realidades estão tomando contornos no Paraná e dependem de cada usina, porém estão contribuindo para demarcar as possibilidades decisórias das firmas quanto às suas capacidades tecnológicas, configurando-se como determinantes da dinâmica tecnológica desse setor. 


\section{Referências}

ALCOPAR. ALCOPAR. Disponível em: 〈http://www.alcopar.org.br〉. Acesso em: 10 Fev. 2005.

ALVES, L. R. A. Transmissão de preços entre produtos do setor sucroalcooleiro do Estado de São Paulo. Piracicaba, SP: ESALQ/ USP, 2002. 117 f. Dissertação (Mestrado).

AZEVEDO, P. F. de. Resenha do livro Agroindústria canavieira no Brasil: evolução, desenvolvimento e desafios. Revista de Economia Política, v.24, n.4 (96), p. 636-639, Out./Dez. 2004.

CAMPOMAR, M. C. Do uso do estudo de caso em pesquisas para dissertações e teses em administração. Revista Administração de Empresas, v.16, p. 25-29, Jul./Set. 1991.

CANUTO, O. Ciclos de vida do produto e vantagens de internacionalização de capacidades tecnológicas, sob uma abordagem evolucionista. In: ENCONTRO NACIONAL DE ECONOMIA, 19., 1991, Curitiba. Anais... Brasília: ANPEC, 1991. p. 313-334.

CÁRIO, S. A. F.; PEREIRA, F. C. B. Inovação e desenvolvimento capitalista: referências histórica e conceitual de Schumpeter e dos neoschumpeterianos para uma teoria econômica dinâmica. Revista de Ciências Humanas Universidade do Extremo Sul Catarinense, Criciúma, SC, v.7, n.1, p.81-102, 2001.

CARVALHEIRO, E. M. Evidências empíricas do impacto da desregulamentação na agroindústria canavieira do Paraná. Toledo, PR: UNIOESTE, 2003. 76 f. Monografia (Graduação) - Colegiado de Ciências Econômicas, Universidade Estadual do Oeste do Paraná, Toledo. 
COUTINHO, L. G. et al. (Coords.). Estudo da competitividade da indústria brasileira. Relatório Final Ministério da Ciência e Tecnologia - MCT/Financiadora de Estudos e Projetos - FINEP/Programa de Apoio ao Desenvolvimento Científico e Tecnológico-PADCT. 1993. Disponível em: 〈http://www.mct.gov.br/publi/Compet/r_final1.pdf >. Acesso em: 3 Abr. 2003.

DAHLMAN, C.; ROSS-LARSON, B.; WESTPHAL, L. Managing technological development - Lessons from the newly industrializing countries. Washington: World Bank Staff, 1985. (Working Papers, n. 717).

DOSI, G. Technical change and industrial transformation. New York: St. Martin's Press, 1984. 338 p.

GIL, A. C. Técnicas de pesquisa em economia. São Paulo: Atlas, 2000.217 p.

GODOY, A. S. Pesquisa qualitativa e sua utilização em administração de empresas. Revista Administração de Empresas, v.35, n. 4, p. 6571, Jul./Ago. 1995.

HAGUENAUER, L.; FERRAZ, J. C.; KUPFER, D. S. Competição e internacionalização na indústria brasileira. In: BAUMAN, R. (Org.). O Brasil e a economia global. 3. ed. Rio de Janeiro: Campus; SOBEET, 1996. p.195-217,

KAEFER, G. T.; SHIKIDA, P. F. A. The genesis of sugar cane industry in Paraná State and its recent development. In: CONGRESSO BRASILEIRO DE ECONOMIA E SOCIOLOGIA RURAL, 38., 2000, Rio de Janeiro. Anais... Rio de Janeiro, 2000. p. 406 (Versão na íntegra em CD-ROM).

LALL, S. Technological capabilities and industrialization. 1992. Disponível em: <http://disciplinas.adm.ufrgs.br/jaragua/bibliograf/>. Acesso em: 9 Abr. 2003. 
ARTINS, J. P. Capacidades tecnológicas da Fiasul Indústria de Fios Ltda. (Toledo-PR). Toledo, PR: UNIOESTE, 2004. $98 \mathrm{f}$. Dissertação (Mestrado).

MORAES, M. A. F. D. Desregulamentação da agroindústria canavieira: novas formas de atuação do Estado e desafios do setor privado. In: MORAES, M. A. F. D. de; SHIKIDA, P. F. A. (Orgs.). Agroindústria canavieira no Brasil. São Paulo: Atlas, 2002. p. 21-42.

MUNHOZ, D. G. Economia aplicada: técnicas de pesquisa e análise econômica. Brasília: Editora Universidade de Brasília, 1989. 300 p.

OLIVEIRA, R. C. de Competitividade - Definição e problemas de mensuração, 2003. Disponível em: <http://www.economiabr.net/colunas/ ceron/competitividade.html>. Acesso em: 9 Abr. 2003.

POSSAS, M. L. Concorrência, inovação e complexos industriais: algumas questões conceituais. Cadernos de Ciência \& Tecnologia, Brasília, v.8, n.1/3, p. 78-97, Jan./Dez. 1991.

ROCHA, E. M. P. da; FERREIRA, M. A. T. Análise dos indicadores de inovação tecnológica no Brasil: comparação entre um grupo de empresas privatizadas e o grupo geral de empresas, 2001. Disponível em: <http://www.ibict.br/cionline/300201/3020108.pdf>. Acesso em: 3 Abr. 2003.

ROSENBERG, N. Inside the black box: technology and economics. Cambridge: Cambridge University Press, 1982. 304 p.

RUFFONI, J. P.; ZAWISLAK, P. A. Technological partnership and capability efforts: thinking about automobile components companies in South of Brazil. In: INTERNATIONAL CONFERENCE ON MANAGEMENT OF TECHNOLOGY, 8., 1999, Cairo, Egito. Anais... MOT: Cairo (Egito), 1999. v.8. Disponível em:<http://nitec.adm.ufrgs.br/ gcars/artigos/parc.tecn.pdf >. Acesso em: 9 Abr. 2003. 
SALLES FILHO, S. L. M. A dinâmica tecnológica da agricultura: perspectivas da biotecnologia. Campinas, SP: UNICAMP, 1993. $261 \mathrm{f}$. Tese (Doutorado) - Universidade Estadual de Campinas, Campinas.

SHIKIDA, P. F. A. A dinâmica tecnológica da agroindústria canavieira do Paraná: estudos de caso das usinas Sabarálcool e Perobálcool. Cascavel, PR: EDUNIOESTE, 2001. 117 p.

SHIKIDA, P. F. A. A evolução diferenciada da agroindústria canavieira no Brasil de 1975 a 1995. Piracicaba, SP: ESALQ/USP, 1997. $191 \mathrm{f}$. Tese (Doutorado).

SHIKIDA, P. F. A.; ALVES, L. R. A. Panorama estrutural, dinâmica de crescimento e estratégias tecnológicas da agroindústria canavieira paranaense. Nova Economia, Belo Horizonte, v.11, n.2, p.123-149, Dez. 2001.

SHIKIDA, P. F. A.; FRANTZ, R. L. Estratégias de atuação da ALCOPAR (PR) em face da desregulamentação setorial e da globalização da economia. In: MONTOYA, M. A.; ROSSETO, C. R. (Orgs.). Abertura econômica e competitividade no agronegócio brasileiro: impactos regionais e gestão estratégica. Passo Fundo, RS: Editora UPF, 2002. p.181-205.

SHIKIDA, P. F. A. et al. Impactos das transformações institucionais e do progresso técnico sobre os fornecedores de cana do Estado do Paraná: uma abordagem preliminar. In: CONGRESSO BRASILEIRO DE ECONOMIA E SOCIOLOGIA RURAL, 42., 2004, Cuiabá. Anais... Cuiabá: SOBER, UFMT, 2004. (versão na íntegra em CD-ROM).

ÚNICA Produção Brasil, 2004. Disponível em: <http:// www.portalunica.com.br/referencia/estatisticas.jsp>. Acesso em: 10 Nov. 2004. 
VIAN, C. E. de F. Agroindústria canavieira: estratégias competitivas e modernização. Campinas, SP: Átomo, 2003. 216 p.

YIN, R. K. Estudo de caso: planejamento e métodos. Porto Alegre: Bookman, 2001, 205 p.

Abstract - The objective of this paper is to analyse the matrix of technological capabilities of the sugar cane industry in Paraná State, showing your characteristic in the ambits of the investments, operation/production, innovation and relationships with the economy. The results of the matrix of technological capabilities show that the fact of not existing great concentrations for technological capabilities, for the advanced level, common in sugar cane industry, it is still derived of the secular subvencionist paradigm that reigned in the section until the nineties. However, the concern with the sectorial survival, mainly in the current deregulation ambient, it is also evidenced in several ambits of the technological capabilities portrayed by some sugar cane mills researched.

Keywords: technological capabilities, dynamics, sugar cane industry, Paraná. 
REVISTA DE ECONOMIA E AGRONEGÓCIO, VOL.3, $N^{o} 3$ 